\section{Surgical Review: International Journal of Surgery Trauma and Orthopedics}

2020 Volume 6 Number 3 May-June

\title{
Laparoscopic ventral hernia repair: Comparison of tacker v/s Monofilament suture
}

\author{
Bagwan L. ${ }^{1}$, Patwa P. ${ }^{2 *}$, Kumar K. ${ }^{3}$ \\ DOI: https://doi.org/10.17511/ijoso.2020.i03.13 \\ $\mathbf{1}$ Latif Bagwan, Consultant GI and Laparoscopic Surgeon, Gateway Clinics and Hospital, Coimbatore, Tamil Nadu, India. \\ 2* Piyush Patwa, Consultant GI and Laparoscopic Surgeon, Gateway Clinics and Hospital, Coimbatore, Tamil Nadu, India. \\ ${ }^{3}$ K. Sendhil Kumar, DNB Surgery, Gateway Clinics and Hospital, Coimbatore, Tamil Nadu, India.
}

Introduction: Hernias may be generally defined as a protrusion of abdominal viscera outside the abdominal cavity through a natural or acquired defect. Transracial sutures penetrate all layers of the abdominal wall, thereby enable fixation of the mesh to the entire fasciomuscular layer of the abdominal wall. In the present study, a comparison between the two most common methods of mesh fixation, i.e. tackers versus sutures was done. Materials and Methods: The totals of 100 patients were included in the study. The study was conducted in the department of the surgery for a period of one year. All the included patients were admitted for laparoscopic repair of primary or ventral hernia. All the patients included in the study were divided into two groups. Group A: patients with tacker fixation and Group B: Suture mesh fixation. Results: Although all the patients in the study presented with swelling in the abdominal region, associated pain was present in 56 of patients, 28 presented with irreducibility, 10 with obstruction, and only 6 patients showed the features of strangulation. The operative time was significantly higher in Group II. Patients in Group I experience more pain post-operatively. The incidence of seromas was higher in Group II. The cost of surgery was significantly higher in Group I compared to Group II. Conclusion: No major complications were encountered during or after the procedure. The formation of seromas was higher in suture fixation. In group A the use of tacks was costly as compared to group B. In the small-sized defect and in anatomical areas, the suture fixation was a better alternative as compared to tacker fixation.

Keywords: Laparoscopic Hernia repair, Primary, Tacker, Mesh, Suture, Ventral

Corresponding Author

Piyush Patwa, Consultant GI and Laparoscopic Surgeon, Gateway Clinics and Hospital, Coimbatore, Tamil Nadu, India.

Email: Piyu_patwa@yahoo.com

\section{How to Cite this Article}

Bagwan L, Patwa P, Sendhil KK. Laparoscopic ventral hernia repair: Comparison of tacker $\mathrm{v} / \mathrm{s}$ Monofilament suture. Surgical Rev Int J Surg Trauma Orthoped. 2020;6(3):215-219.

Available From

https://surgical.medresearch.in/index.php/ijoso/artic le/view/171

\section{To Browse}

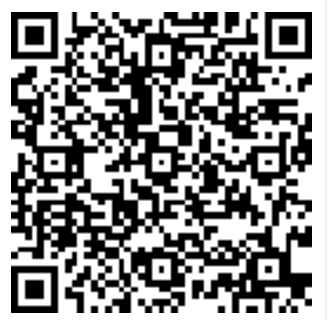

Manuscript Received 2020-04-15

Conflict of Interest No

Review Round 1
2020-04-25
Funding
Nil

2020 by Latif Bagwan, Piyush Patwa, K. Sendhil Kumar and Published by Siddharth Health Research and Social Welfare Society. This is an Open Access article licensed under a Creative Commons Attribution 4.0 International License https://creativecommons.org/licenses/by/4.0/ unported [CC BY 4.0].

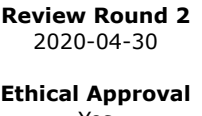

Accepted 2020-05-05

Note 


\section{Introduction}

Hernias may be generally defined as a protrusion of abdominal viscera outside the abdominal cavity through a natural or acquired defect. The Latin word hernia means rupture or tear. A protrusion of any viscus from its proper cavity is denominated a hernia [1]. The protruded parts are generally contained in a bag by a membrane with which the cavity is naturally invested.

Inguinal hernias are among the most common problems encountered by the Surgeon. Seventy-five percent of all abdominal wall hernias occur in the groin. Indirect hernia outnumbers direct hernias by about 2:1 with femoral hernia making up a very small proportion [2].

Sir Astley Cooper stated, "No disease of the human body, belonging to the province of the surgeon, requires in its treatment a better combination of accurate anatomical knowledge with surgical skill than hernia in all its varieties". Thorough knowledge is a must for any surgeon $[1,3]$.

Though hernia is a very common ailment amongst surgical patients, irreducibility, obstruction, and strangulation are its commonest complication encountered in surgical practice as an acute emergency $[4,5]$.

The identification of risk factors like age, sex, type of hernia, presenting symptoms, and associated pre-existing medical illness helps give priority in admission to such patients. The delay in surgery in a case of complicated hernia increases the morbidity and mortality in such patients $[5,6]$.

Theoretically, there will be no recurrence if the basic principles of surgical repair including wide coverage and secure fixation are adhered to [7]. The common causes of recurrence are technical, which include a missed hernia, inadequate mesh overlap, and inadequate mesh fixation resulting in failure to cover the defect or migration of part or whole of the mesh [8].

Some surgeons advocate that sutures are unnecessary for mesh fixation because of the excellent incorporation of mesh into the abdominal wall [9]. However, many cases of mesh migration and contraction of various types of mesh have been reported. These events after LVHR can predispose to recurrence.

The two most common methods of mesh fixation
Are metallic tacks and transracial sutures. Although mesh fixation with tacks is convenient and timesaving in the laparoscopic repair of incisional and ventral hernias, the tensile strength of a mesh fixed by transfacial sutures is greater than when fixed by tacks [10].

Transfacial sutures penetrate all layers of the abdominal wall, thereby enable fixation of the mesh to the entire fasciomuscular layer of the abdominal wall. In the present study, a comparison between the two most common methods of mesh fixation, i.e. tackers versus sutures was done.

\section{Materials and Methods}

The totals of 100 patients were included in the study. The study was conducted in the department of the surgery for a period of one year. All the included patients were admitted for laparoscopic repair of primary or ventral hernia.

The patients were informed about the study and the written informed consent was taken from all the included patients. The ethical committee of the institute was informed about the study and the ethical clearance certificate was obtained from them.

All the patients included in the study were divided into two groups. Group A: patients with tacker fixation and Group B: Suture mesh fixation. The inclusion criteria for the study were as below: small size of the hernia defect, primary ventral hernias, and incisional hernias not operated earlier.

Exclusion criteria were as follows: patients were recurrent hernias, the large size of the hernia, and patients were diabetes and skin infection were excluded from the study. All patients received preoperative antibiotic prophylaxis. All patients were operated under general anesthesia.

In case of a defect in the lower abdomen, the urinary bladder is decompressed by using Foley's catheter. After the creation of pneumoperitoneum with a Veress needle at the umbilicus or left hypochondrium, a $12 \mathrm{~mm}$ laparoscopic port for a 30-degree telescope was introduced away from the left lateral margin of the defect in the left flank.

Depending upon the location of the hernia defect, two $5 \mathrm{~mm}$ ports were placed. Omental and bowel adhesions were taken down using monopolar diathermy or scissors. Identification of the defect was done and additional defects were looked and defects were measure from outside. 
A mesh of appropriate size was used to overlap all the defects in a single piece with a margin of at least $4-5 \mathrm{~cm}$. Any deficient coverage at any margin was supplanted with an extra patch of mesh.

In Group I, mesh fixation was done with a $5 \mathrm{~mm}$ tacker (Protack, Autosuture, Tyco Healthcare, USA) along with 4 corners 1-0 polypropylene transfacial sutures. The tacks were placed at all four corners and then at $1-2 \mathrm{~cm}$ distance along the peripheral margin and again the second row of tacks were placed along the defect margin (Double crown technique).

In Group II, after the 4 corners, 1-0 polypropylene transfacial sutures were tied subcutaneously, additional 1-0 polypropylene sutures were passed through the abdominal wall using a modified $16-\mathrm{G}$ epidural needle and then the other end of the suture was grasped with a suture passer and brought outside through the abdominal wall. Sutures were tied outside subcutaneously. The sutures were placed $2-3 \mathrm{~cm}$ apart.

At the end of the procedure, pneumoperitoneum was decompressed and sheath at $12 \mathrm{~mm}$ ports closed with polyglactin 910 (Vicryl) 2-0. The operation time was measured from the skin incision given for Veres's needle insertion till complete closure of all port sites.

\section{Results}

A total of 100 patients were included in the study. The patients with ventral or primary hernia were admitted, investigated, and operated and studied. The smallest patient was age 19 years and the oldest patient was age 90 years. The maximum patients were of age group 46-65 years.

Males were found to be predominant in the study as compared to females with 90 patients were males and 10 females. Although all the patients in the study presented with swelling in the abdominal region, associated pain was present in 56 of patients, 28 presented with irreducibility, 10 with obstruction and only 6 patients showed the features of strangulation.

The patients have divided into two groups: Group A and Group B. Incisional hernia was the most common type seen in both the groups followed by primary ventral hernias.

The majority of the defects were seen in the infraumbilical region in both groups. Heavyweight
Polypropylene was the most commonly used mesh followed by lightweight polypropylene polydioxanone-oxidized regenerated cellulose composite mesh.

The operative time was significantly higher in Group II. Patients in Group I experience more pain postoperatively. The incidence of seromas was higher in Group II. The cost of surgery was significantly higher in Group I compared to Group II.

The overall Post-operative complications rate for Group 1was significantly higher than Group 2. Important postoperative complications in both groups were hematomas, wound infections, airway infections, and urinary tract infection

Table-1: Age distribution of patients.

\begin{tabular}{|l|l|}
\hline \multicolumn{1}{|c|}{ Age } & \multicolumn{1}{c|}{ Patients } \\
\hline $15-25$ & 12 \\
\hline $26-35$ & 20 \\
\hline $36-45$ & 10 \\
\hline $46-65$ & 50 \\
\hline $66-75$ & 5 \\
\hline $76-85$ & 02 \\
\hline $86-95$ & 01 \\
\hline
\end{tabular}

Table-2: Clinical presentation of patients.

\begin{tabular}{|l|l|}
\hline \multicolumn{1}{|c|}{ Symptoms } & \multicolumn{1}{c|}{ Patients } \\
\hline Pain & 56 \\
\hline Irreducibility & 28 \\
\hline Obstruction & 10 \\
\hline Strangulation & 6 \\
\hline
\end{tabular}

Table-3: Complications in Group 1 and Group 2.

\begin{tabular}{|l|l|l|}
\hline \multicolumn{1}{|c|}{ Complications } & \multicolumn{1}{c|}{ Group 1 } & Group 2 \\
\hline Hematoma & 5 & 4 \\
\hline Wound infections & 7 & 5 \\
\hline Airway infections & 6 & 4 \\
\hline Urinary tract infection & 7 & 3 \\
\hline
\end{tabular}

\section{Discussion}

In this present study, as shown in the above table, the majority of patients were between 46 to 65 years. In this study, they made $46 \%$, which correlates well with the study done by Alan Robbins [11]. The youngest in this study was 19 years old and the eldest was 90 years old.

In this study, $90 \%$ of the patients were male, and less than $10 \%$ were female which is almost the same as the study done by Page B [12]. The low incidence of inguinal hernia in females is due to the 
Difference in the embryology and anatomical contents.

Though it is obvious that the inguinal hernia patient's chief complaints are swelling in the region of the groin, some sort of discomfort or pain is always associated as shown in the table above. In this present study, pain or discomfort was present in 56 patients as compared to Chandiramani [13] series, which is almost the same as the present study.

Also, the study reveals that a complicated presentation of inguinal hernia is less common in this modern era of health awareness. People seeking for surgery before getting complicated are admirable. In my study, only one female patient presented with a strangulated type of inguinal hernia.

In this present study, the age range of the patients in the mesh group was 18-85 years and the nonmesh group was $20-90$ years, who were randomized and operated. The non-mesh repair included darning repair using prolene, Bassini repair, Halsted repair. In the mesh, repair mesh was placed on lay by the open method.

The operative time was significantly higher in Group II. Patients in Group I experience more pain postoperatively. The incidence of seromas was higher in Group II. The cost of surgery was significantly higher in Group I compared to Group II.

Currently, the most popular method of mesh fixation being used worldwide has been the use of tacks along with 4 corner transfacial sutures. The use of only transfacial suture fixation has not become very popular because of certain drawbacks. Suture fixation is time-consuming and it is difficult to insert these transfacial sutures in certain anatomical areas like the pelvis, above the subcostal margin, and laterally in the flanks [14].

Sometimes, there are chances of bowel injury during the insertion of the Suture Passer needle. There is also certain concern about the cosmetic appearance of these transfacial suture puncture sites over the skin of the abdominal wall after surgery.

\section{Conclusion}

No major complications were encountered during or after the procedure. The formation of seromas was higher in suture fixation. In group A the use of tacks
Was costly as compared to group B. In the smallsized defect and in anatomical areas, the suture fixation was a better alternative as compared to tacker fixation.

\section{What does the study add to the existing knowledge?}

Absorbable tacker mesh fixation may be a safe, feasible, and time-saving alternative to polypropylene suture fixation. However, this study only showed the initial absorbable mesh fixation device experiences in laparoscopic pectopexies. Further prospective comparative studies with more significant numbers of patients are needed to show long-term results.

\section{Author's contribution}

Dr.Latif Bagwan: Formulated the aims and objectives with study design and helped in data collection from the medical record department.

Dr. Patwa P: Contributed to the preparation of the manuscript and data analysis.

Dr. K. Sendhil Kumar: Contributed to data collection, manuscript writing, and data analysis

\section{Reference}

01. Dunna V, Mokati UK, Tata KP, Bathina NB, Nowsheen M, Ambati DL, et al. Clinical study to compare the short term outcomes in six months follow up period with Respect to open mesh and non mesh repair based on randomization. J Med Sci Clin Res. 2019;7(8).

[Crossref]

02. Dabbas N, Adams K, Pearson K, Royle G. Frequency of abdominal wall hernias- is classical teaching out of date?. JRSM Short Rep. $2011 ; 2(1) 1-6$. doi: [Article] [Crossref]

03. Sivakumar G. A prospective study evaluating the use of polypropelene mesh in emergency surgery of obstructed hernias (Doctoral dissertation, Madurai Medical College, Madurai). tnmgrmu. 2018.

[Crossref]

04. Alvarez J, Baldonedo R, Bear I, Solis J, Alvarez $P$, Jorge J. Incarcerated groin hernias in adultspresentation and outcome. Hernia. 2004;8(2)121-126. doi: [Article] [Crossref] 
05. Srinath S, Hungund $P$, Suma K. Complicated groin hernias--risk factors, conservative management and timing of surgical management. J Evol Med Dental Sci. 2013;2(34)6502-6509.

[Crossref]

06. Ganie FA, Lone H, Lone GN, Wani ML, Ganie SA. Delayed presentation of traumatic diaphragmatic hernia- a diagnosis of suspicion with increased morbidity and mortality. Trauma Mon. 2013;18(1)12-16. doi: [Article] [Crossref]

07. Kawaguchi N, Matumoto S, Manabe J. New method of evaluating the surgical margin and safety margin for musculoskeletal sarcoma, analysed on the basis of 457 surgical cases. J Cancer Res Clin Oncol. 1995;121(9-10)555-563. doi: [Article] [Crossref]

08. Lowham AS, Filipi CJ, Fitzgibbons Jr RJ, Stoppa R, Wantz GE, Felix EL, et al. Mechanisms of hernia recurrence after preperitoneal mesh repair, Traditional and laparoscopic. Ann Surg. 1997;225(4)422-431.

doi: [Article] [Crossref]

09. Khajanchee Y, Urbach D, Swanstrom L, Hansen P. Outcomes of laparoscopic herniorrhaphy without fixation of mesh to the abdominal wall. Surg Endosc. 2001;15(10)1102-1107.

doi: [Article] [Crossref]
10. Bansal VK, Misra MC, Kumar S, Rao YK, Singhal $\mathrm{P}$, Goswami A, et al. A prospective randomized study comparing suture mesh fixation versus tacker mesh fixation for laparoscopic repair of incisional and ventral hernias. Surg Endosc. 2011;25(5)1431-1438. doi: [Article] [Crossref]

11. Awad SS. Evidence-based approach to hernia surgery. Am J Surg. 2004;188(6A)1S. doi: [Article] [Crossref]

12. Page B, Paterson C, Young D, O'Dwyer P. Pain from primary inguinal hernia and the effect of repair on pain. $\mathrm{Br}$ J Surg. 2002;89(10)13151318.

doi: [Article] [Crossref]

13. Chandiramani VA, Katara AN, Pandya SM, Nair NS. Prolene hernia system in the tension free repair of primary inguinal hernias. Indian J Surg. 2003;65(6)488-491.

[Crossref]

14. Gilbert AI. Inguinal hernia repair- biomaterials and sutureless repair. Persp Gen Surg. $1991 ; 2 ; 113-129$.

[Crossref] 